\title{
Reflexiones sobre los pueblos originarios del pacífico, centro y norte de Nicaragua.
}

Reflection on the original peoples of the pacific, central and northern Nicaragua

\author{
Uwe Paul Cruz Olivas \\ Historiador y Arqueólogo \\ Presidente de la Fundación Científica Cultural Ulúa Matagalpa y Asesor cultural del Pueblo \\ Indígena Matagalpa \\ Id Orcid: https://orcid.org/0000-0001-9925-1640 \\ Correo: uwepaulcruz@gmail.com
}

\section{Resumen}

A lo largo y ancho de Nicaragua encontramos diferentes expresiones culturales de los pueblos originarios, quienes arduamente luchan por conservar sus bosques, sus tradiciones, formas de organización social, formas de hacer política y de maniobrar sus asuntos económicos y sociales en plena libertad. Pese a ello, los pueblos indígenas del centro norte de Nicaragua se encuentran en un complejo laberinto étnico, al asumir falsos positivos ${ }^{1}$ en relación a su origen histórico.

Es decir, la construcción del discurso y de la identidad étnica en algunos pueblos del centro y norte, gira alrededor un falso positivo cultural denominada "chorotega", dicha aseveración tergiversa gran parte de la historia de los pueblos indígenas de las Segovia. En el presente ensayo, abordaré las tramas étnicas y políticas relacionadas a la identidad cultural de los pueblos indígenas del centro norte de Nicaragua, quienes asumen una identidad cultural que no concuerda con la historia, la lingüística y la antropología de la región. Dicho ensayo, tiene el propósito de reivindicar más allá, de las prácticas y tradiciones los asuntos de la auto identificación étnica, en las comunidades originarias de las Segovia. Para ello, retomé elementos de la antropología cultural y de la arqueología nacional, que permita dilucidar los orígenes y los procesos históricos de los pueblos en cuestión.

Asimismo, la hipótesis que ubico en la antropología nacional tiene como base, debatir el discurso de los pueblos denominados "chorotega del centro y norte" a través de los registros primarios, los resultados de la arqueología en los últimos 20 años, en la región centro y norte. También, retomaremos los estudios lingüísticos de Alfonso Cónstenla en la región antes mencionada. Partiendo, de una corriente interdisciplinaria de la antropología del sur, que impulsa el reconocimiento de la identidad originaria de los pueblos, desde su origen étnico, historia en común, prácticas cotidianas y estructura sociocultural posmoderna existente en la región.

Palabras Claves: origen cultural, identidad étnica, auto identificación, pueblos de las Segovia, falsos positivos.

\footnotetext{
1 La palabra Falso Positivo es utilizada en la terminología de la medicina como "Hallazgo anormales en los exámenes cuando la enfermedad no existe", siendo una información falsa (Antonio. J.2013).

2 Según las narraciones de Torquemada (1975:3:452-454), menciona que la palabra "Chorotega" viene de la voz nahua que significa "Los Desplazados" cuyo grupo étnico son los Mangues. Quienes migraron a la provincia de Nicaragua entre el 800 al 850 d.C.
} 


\begin{abstract}
Throughout Nicaragua, we find different cultural expressions of indigenous peoples, who struggle hard to conserve their forests, their traditions, forms of social organization, ways of doing politics and maneuvering their economic and social affairs in full freedom. Despite this, the indigenous peoples of north central Nicaragua find themselves in a complex ethnic labyrinth, assuming false positives in relation to their historical origin.

That is, the construction of discourse and ethnic identity in some towns in the center and north, revolves around a false cultural positive called «Chorotega», this assertion distorts much of the history of the indigenous peoples of the Segovia. In the present essay, I will approach the ethnic and political plots related to the cultural identity of the indigenous peoples of the north center of Nicaragua, who assume a cultural identity that does not agree with the history, linguistics and anthropology of the region. Said essay, has the purpose of vindicating beyond, of the practices and traditions the subjects of the ethnic selfidentification, in the original communities of the Segovia. To do this, I returned to elements of cultural anthropology and national archeology, to elucidate the origins and historical processes of the peoples in question.
\end{abstract}

Likewise, the hypothesis that I place in the national anthropology has as its base, to debate the discourse of the people denominated «Chorotega of the center and north» through the primary registers, the results of the archeology in the last 20 years, in the central region and north. Also, we will resume the linguistic studies of Alfonso Cónstenla in the aforementioned region. Starting from an interdisciplinary current of southern anthropology, which promotes the recognition of the original identity of peoples, from their ethnic origin, common history, daily practices and postmodern socio-cultural structure in the region.

Keywords: cultural origin, ethnic identity, self identification, peoples of the Segovia, false positives. 


\section{Introducción}

Durante los últimos años las investigaciones antropológicas han proporcionado información sobre los pueblos originarios del centro norte del país, recuperando valiosísimos aportes sobre sus modos de vida, subsistencia cotidiana, espiritualidad, medicina natural y su pasado prehistórico. El avance en materia de investigación cultural nos permite continuar penetrando en los trabajos de indagación del pasado, presente y del futuro de los pueblos originarios del centro norte de Nicaragua. Por otro lado, sabemos que la continuidad cultural de los grupos étnicos en el territorio es una realidad antropológica innegable, pese a ello, la historia de despojo y discriminación histórica que viven los pueblos indígenas, por parte de las clases dominantes del país, sigue siendo un tema vigente en las relaciones de producción de las Segovia.

Además, las relaciones de poder entre el mestizo y el indígena siguen siendo desiguales; el patronato y los sistemas feudales agrarios continúan cercenando los bosques y las fuentes de agua en los territorios indígenas. Sin embargo, esta desalentadora realidad fuerza a los oriunda a retomar otra postura más beligerante en los temas de interés comunitarios, relacionado al patrimonio natural, cultural y espiritual. Aparte, del compromiso con los asuntos relacionados al respeto de los territorios ancestrales, la protección de los bosques y el agua, como del patrimonio cultural, la autonomía política y la económica solidaria.

Desde el reconocimiento de los pueblos indígenas y la firma del convenio 169 de la OIT; los grupos étnicos empezaron a organizarse en todo el país y a partir del año 2012 publicaron un libro titulado "nosotros si existimos". Entonces se fueron formando diversas organizaciones que velan por los derechos de los pueblos originarios, sin embargo, estas tienen grandes debilidades en materia de arqueología, antropología o historia de los pueblos en cuestión, así se alteró los orígenes comunes de los pueblos originarios de las Segovia, como su pasado histórico, su presente y su futuro. Es por ello, que el presente estudio, tiene un amplio componente interdisciplinario con el objetivo de analizar los laberintos de la auto identificación en los pueblos oriundos del centro norte de Nicaragua. A partir de los elementos arqueológicos y antropológicos que nos permita dilucidar los orígenes en común de los grupos étnicos del centro norte, partiendo desde la lógica de la identidad culturales, la consciencia étnica y los errores históricos presentes en la antropología nacional

\section{Metodología de la Investigación}

Para el presente ensayo, se retoma como base principal la multidisciplinaridad de la ciencia antropológica a través de la etnografía, arqueología e historia de la región centro y norte, asimismo, se puso en práctica el, método investigativo acción participativa en las comunidades indígenas de las Segovia, particularmente en los pueblos originarios de Lítelpaneca, Matagalpa, Sébaco, Muy muy, Jinotega y Pantasma.

Además, de la observación directa y la experiencia de diversas empresas de trabajo de campo realizados por diferentes colegas arqueólogos y antropólogos. Para ello, se creó un plan metodológico conformado por una variedad de inventivas y técnicas, de las ciencias arqueológicas, históricas y antropológicas, que permite obtener un plano más amplio de la realidad en cuestión y los fenómenos sociales de contexto. Las actividades, se dividieron en tres etapas básicas en momentos diferentes los cuales fueron: trabajo de oficina, trabajo de campo y de laboratorio.

Durante la faena de oficina se realizó el proceso de planificación referentes a la visita de cada una de los pueblos, además, de la consulta de fuentes arqueológicos, históricos y antropológicos de los pueblos indígenas del centro y norte de Nicaragua. Cabe mencionar, que se visitó y documentos diferentes sitios arqueológicos en los pueblos antes mencionados con el

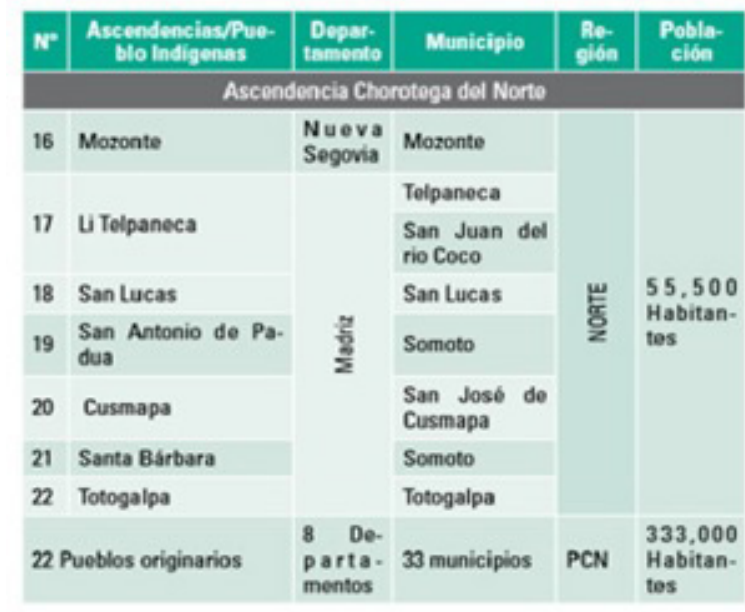


fin de obtener muestras de la materialidad cultural de la prehistoria de los grupos aborígenes de las Segovia. Además, de la interacción con los líderes y autoridades de cada uno de los pueblos antes mencionados para ejecutar el plan de documentación, caracterización y análisis de la materialidad cultural recuperado en cada uno de los pueblos antes mencionados.

Asimismo, fue sustantivo el análisis bibliográfico sobre el tema y las investigaciones comparativas entre las comunidades indígenas del centro y norte de Nicaragua. Principalmente las entrevistas a los presidentes de Sébaco, Matagalpa, Jinotega y Lítelpaneca que nos muestran su identidad étnica y la expresión ideológica de la pertenencia a una determina configuración social y política territorial.

\section{Origen cultural de las identidades de los pueblos indígenas del centro y norte de las Segovia.}

En Nicaragua existen 22 pueblos indígenas en el pacifico centro y norte más 16 regiones territoriales en la región del caribe, los cuales comparten características propias y diversas.

Para poder exponer los componentes culturales de las identidades de los pueblos indígenas de las Segovia, tengo que partir por conocer los orígenes étnicos de las comunidades nativas. Esto me permitirá, analizar holísticamente los significados de la autoconciencia étnica, además, de comprender en que consiste el laberinto de la auto identificación entre los pueblos indígenas del centro y norte de Nicaragua. Para ello, es ineludible tomar en cuenta las investigaciones arqueológicas en el territorio, además, de los valiosos componentes culturales que precisan la existencia y el reconocimiento de las familias indígenas a partir del origen ancestral. Donde la categoría de pertenencia se debe analiza más allá del apego al territorio, al parentesco familiar y a la historia misma (Andino, 2017).

En primer lugar, la identidad étnica "es la expresión ideológica de la pertenencia a una determinada configuración social, que implica que los individuos asumen y sean reconocidos como miembros de dicha configuración social" (Bonfil, 1988). A mi criterio, la construcción de la identidad se articula a las prácticas y costumbres diarias que dan significado al mundo de las personas, desde donde los pueblos indígenas reivindican su pasado, a través de la ciencia social al servicio del pueblo, para reconstruir las identidades grupales, regionales y nacionales.

Los documentos etnohistóricos, primarias de la conquista en el territorio de las Segovia son muy escasas, sin embargo, el cronista Fernández de Oviedo menciona rápidamente que los habitantes de las partes altas de Nicaragua hablaban una de las cuatro lenguas más utilizada en la provincia de Nicaragua; la cual es considerada diferente a la de los chorotegas y nicarao (Espinosa, 1992). Otra referencia de los cronistas de indias, es acerca de la manera en que estos indígenas de las Segovia utilizaban los árboles de pino para producir un tinte que luego eran utilizado en los tatuajes (Oviedo, 1976:302).

También, más tardío son los datos del censo español de 1581 y los relatos de Cibdad Real (1586), como de un sinnúmero de Frailes que estuvieron en la cristianización del centro norte de Nicaragua, entre ellos Fray Juan de Albuquerque (1606) quien llevo indígenas de Sébaco al corregimiento de León y menciona que hablaban una lengua en común (Cruz, 2017).

Por otro lado, tenemos los estudios lingüísticos realizados por Dr. Carl Berendt (1855) quien recibió un vocabulario de 94 palabras y algunas frases facilitadas por el padre Víctor de Jesús Noguera sacerdote ordenado en 1853 en la ciudad de Matagalpa, quien había aprendido a dominar la lengua que él llamaba popolu$\mathrm{ca}^{3}$. Y de acuerdo al sacerdote la lengua se hablaba en San Ramón, Muy muy, Boaco, Sébaco, Telpaneca, Palacagüina, Yalagüina, Condega, Totogalpa, Somoto Grande y se había extendido en tiempos pasados al departamento de Chontales (Kühl, 2010).

Así mismo, el lingüista Daniel Brinton (1891) y Walter Lehmann (1910) son los que van a denominarle lengua Matagalpa y Lehmann las relaciona con las lenguas Mayanngnas y Miskit, en base a información histórica, toponimia y la glotocronología de la región centro norte y caribe del territorio nicaragüense. Por otro lado, en términos estrictamente arqueológicos suponemos que los grupos originarios del centro norte de Nicaragua, denominado por los españoles en diferentes momentos como: chontales, popoluca, parrastra, ulúas, jicaques y montañeses (Oviedo 1851-55). Son

3 En referencia a la lengua Ulúa Matagalpa hablada en el Centro Norte de Nicaragua, sur de Honduras y oriente del Salvador. 
las tribus originales de las Segovia y su nombre más aceptable probablemente puede ser "uluas-matagalpa" esta suposición no es soló compartida por muchos investigadores nacionales e internacionales de reconocida trayectoria científica, sino que apoyan dicha propuesta académica porque permite conocer mejor la prehistoria de las Segovia.

Entre ellos, los estudios realizados por la arqueóloga de Newton (1987), como los del geógrafo Jaime Incer (1992), los de la etnohistoriadora Eugenia Ibarra (1994) y Lara Pinto (1991) y un poco más temprano los trabajos de Stone (1941), Werner (1995), Espinoza (1995) Kühl (2010) y Rizo (2014). Todos ellos, coinciden en un origen en común de todos los grupos étnicos de las Segovia, asimismo, Incer afirma que los conjuntos de personas que habitaron el noreste de Nicaragua estaban lingüísticamente relacionados, y el escribe que:

\begin{abstract}
"Parece que los Ulúas-Matagalpas-Chontales corresponden a un sólo grupo lingüístico que ocupaba la región Noroeste de Nicaragua y las bajuras alrededor del golfo de Fonseca, de la misma manera como lo eran los Lencas y Jicaques que vivían en las continuas montañas de centrales de Honduras a principios del siglo XVII" (Incer:1990:250).
\end{abstract}

También, los últimos trabajos lingüísticos de Cónstenla (1994) e Ibarra (1994), apoyan la tesis de que en Honduras se habló Matagalpa, el mismo nombre de su capital Tegucigalpa lo indica. Dicha hipótesis concuerda con Stone (1957:80), cuando describe a los Matagalpas como un grupo que se extendía de Nicaragua hacia el oeste y en el departamento de El Paraíso en el este de Honduras, en la zona de Choluteca. Para los especialistas de los grupos Matagalpa se han clasificados lingüísticamente de varias maneras; por una parte, se considera que estos pertenecen al tronco Misumalpense como lo sostienen varios investigadores. Por ejemplo, Cónstenla (1994) afirma que:

"El Matagalpa es uno de las cinco lenguas integrantes de la estirpe Misumalpense cuya propuesta fue acertadamente hecha por Walter Lehmann, que incluiría a los sumus el Miskit y el Ulúa, y el Matagalpa y el Cacaopera" (Pag.195).
Las investigaciones arqueológicas que se llevaron a cabo en las Segovia y otros datos provenientes de áreas ocupadas por grupos de origen Matagalpas (Gorin:1990). Indican que en la prehistoria del centro y norte de Nicaragua este grupo étnico controladaba gran parte del territorio nacional, formando parte de una estructura étnica dominante en gran parte del territorio septentrional.

Asimismo, los avances de la arqueología indican que estos antiguos grupos culturales del centro norte eran una población con un sistema social con jerarquía política, división del trabajo establecido y formas de organización tradicional consuetudinario (Hoppes, 1992). Sin embargo, en Nicaragua algunas organizaciones no gubernamentales y el Estado mismo, han tergiversado el origen étnico de algunos pueblos del centro norte adjudicándoles un supuesto origen "chorotega" utilizando la misma tesis de 1967 de Guerrero y Soriano, quienes choroteguisaron y nahualizaron todo el centro norte del territorio nacional.

Por otro lado, según Cónstenla (1994) afirma que "el origen de las primeras oleadas migratorias de Mesoamérica que se asentaron en la provincia de Nicaragua, sobre el 800 d.C., fueron los chorotegas mangue, originarios del Soconusco de Chiapas, al igual que los nicaraos, según la narración del cronista Torquemada, quien agrega que estas migraciones fueron debido a la presión ejercida por el pueblo Olmeca (Pág. 200). En resumen, el origen de los mangue es Chiapas, migraron después del 850 d.C., y debido a las ultimas migraciones de los nicaraos, ocupan un territorio fragmentado, ocupando las dos costas de los lagos y toda la planicie del oeste y norte de Managua, incluyendo Carazo, León y Granada hasta el río Ochomogo, línea divisoria con los nicaraos (pag.133)

Pese a dichos estudios, los pueblos de Sébaco, Muy muy, Li-Telpaneca, Mozonte, Jinotega, Pantasma, Cusmapa, Santa Bárbara, San Antonio de Padua, San Lucas y Totogalpa se auto identifican bajo el término "chorotega del centro y norte", Sin embargo, hasta los momentos no explican cómo fue que llegaron a la región de las Segovia y bajo que, contexto histórico llegaron a las montañas del septentrión. También, no explican si estos grupos que huyeron de la colonización, y luego se mesclaron con los oriundos de las Segovia, al mismo tiempo no explican porque dicen ser "chorotegas" y la otra contradicción es que a los topónimos regionales le buscan una etimología "nahua". Estas inconsisten- 
cias sólo pueden ser superados bajo una antropología y arqueología nicaragüense crítica, de rigor científica y analítica. Para el presidente del pueblo indígena de Lítelpaneca Genaro Martínez (2014) nos dice

"Lítelpaneca es un pueblo cerca del río coco, desde la antigüedad es un puerto de montaña, nuestro pueblo fue denominado como chontales en las crónicas antiguas, pero nosotros nos auto identificamos bajo el termino de chorotegas del norte $y$ pertenecemos a la coordinadora chorotega".

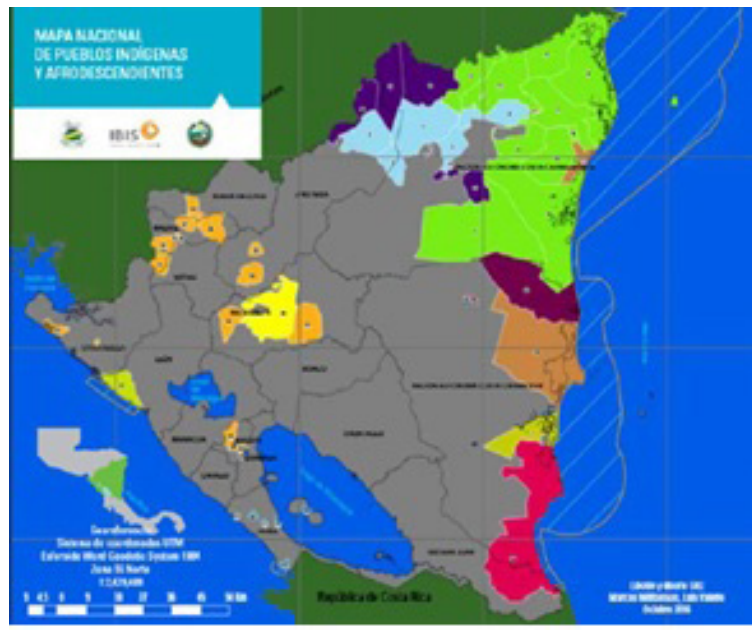

De esta manera, vemos que el líder indígena asume una identidad propia y se auto identifica con un pueblo y origen cultural denominada "chorotega", grupo ubicado en la región del Pacifico y los grandes lagos, sin embargo, su grupo en mención no es originario de las Segovia y la construcción de los grupos chorotegas del centro y norte es un constructo no comprobado, por la antropología y la arqueología. Además, que el museo de la cultura de Lítelpaneca las evidencias arqueológicas, históricas, lingüísticas y antropológica demuestran una vinculación cultural y étnica no "chorotega", Pese a ello, en la región de las Segovia sigue habiendo pueblos indígenas con testimonios de vida, con idiosincrasia, con valores culturales, con liderazgo social, con formas de organización y producción, todas ellas con una historia general en común.

Este hecho abre una amplia discusión antropológica que permita reivindicar el etnos de los pueblos indígenas de las Segovia, desde donde, tiene que partir la construcción de la identidad cultural de las comuni- dades étnicas, siendo este un elemento complejo en la modernidad. Pese a ello, en Nicaragua se reconoce la existencia de los Pueblo del Pacifico, Centro y Norte como parte del Estado nacional plurilingüe y multicultural, desde entonces ellos han planteado:

iNosotros si Exitismo! "Somos más de 333,000 hombres y mujeres chorotegas, cacaoperas/Matagalpa, Xtu/Suttiabas y Nahoas. En nuestras mentes y corazones arde el espíritu de nuestros ancestros: de Diriangen, Nicarao, Sasle, Adiact, Agateyte, Yaguare, Nacacheri, Tenderí y Mosunse. Conservamos el sendero de nuestros abuelos y abuelas que nos enseñaron que somos parte de toda creación que es la fuente de la vida. Aprendimos que cuidar nuestra madre tierra debe de ser una vivencia diaria, igual como cuidarnos nosotros mismos". (APRODIN, 2012).

Sabemos que la búsqueda de una solución a la llamada cuestión étnico nacional ha constituido en los tiempos modernos, uno de los mayores y más complejos desafíos sociopolítico para la antropología nicaragüense. Al mismo tiempo, podemos analizar como APRODIN ${ }^{4}$ integra en la lista de pueblos del centro y norte a los Cacaopera o Kakawira de San Miguel, en El Salvador. Grupo a fin a los pueblos Matagalpa que quedaron aislado durante la penetración de los grupos chorotegas por el golfo de Fonseca en el (800 d.c.) y los Nahuas (1200 d.c.). Siendo el Cacaopera y el Matagalpa idiomas bastantes cercanos, la distancia entre estas dos lenguas puede ser comparada a la que existe entre el italiano y el español, o el portugués. (Salamanca, 2016).

Estos datos son provenientes de las fuentes de la lingüística y la arqueología nicaragüense, sin embargo, las poblaciones indígenas y sus líderes siguen auto identificándose con la cultura "chorotega" sin saber que la construcción de este personaje histórico no tiene fundamento arqueológico, lingüístico e histórico para las Segovia. Tal es el caso del ex presidente del pueblo indígena de Sébaco, Víctor Chavarría (2018) quien dice

"La verdad que nosotros decimos que somos chorotegas, pero no tenemos pruebas para demostrarlo, decimos eso porque los ancianos lo afirmar y porque así no reconoce el Estado de Nicaragua y $O N G$ 's.

4 Consejo de Pueblo Indígenas del Pacifico Centro y Norte. 
El testimonio es muy franco cuando dice que no saben a ciencia cierta cómo demostrar su propia identidad étnica, por otro lado, en los datos estadísticos y en las fichas de caracterización de los pueblos del centro y norte de Nicaragua, se refleja la ascendencia "Chorotega del norte" como uno de los grupos étnicos con mayor población viva y lo ubican con más de 55, 500 habitantes aproximadamente. (APRODIN, 2012).

De esta manera, es que podemos apreciar el falso positivo que se comente con el sujeto étnico de las Segovia, a quien no se le está reivindicado su identidad autentica, en eso consiste, los laberintos de auto identificación en la región del centro norte. Donde los pueblos ulúa-matagalpa constituyeron un mismo grupo cultural, que habitaron desde tiempos inmemorables en el centro y norte de Nicaragua, sur de Honduras y oriente del El Salvador. Y de los que actualmente, quedan los pequeños reductos que presentamos en la figura (1), por otro lado, las comunidades de las Segovia, están constituidas bajo un tramado de prácticas culturales con raíces prehispánicas y topónimos de la lengua matagalpa. También, estos pueblos mantienen sus propios conocimientos tradicionales que los conecta con su memoria histórica, arraigado a su sistema de creencias, que a cómo puedo inferir, es quizás una de las áreas más evidentes de la conexión de la cultural espiritual con prácticas empíricas. No obstante, también existe un apego a la cultura espiritual, a la tierra, a la superstición y, además, de los símbolos lingüísticos, los topónimos de las comarcas, los cerros y el territorio ancestral. Es decir, existen elementos de la cultura ancestral que se conecta directamente con la población indígena actual, a pesar de que existe cierto rechazo a este vínculo étnico y a sus saberes, por una parte, de la sociedad clasista neoliberal de Nicaragua.

Por otro lado, los indígenas del centro se encuentran en otras condiciones un poco más favorables que los mencionados en la figura (2), digo esto porque se supone que, si conservan grandes extensiones de tierra, tienen un mejor nivel de vida que los indígenas de la alta Segovia. Sin embargo, esta afirmación no es ley pues en Matagalpa hay muchos problemas con indígenas en extrema pobreza y sin tierras.

Siendo el territorio la principal fuente de producción y subsistencia, pese a esa realidad, muchos buscan como migrar a los principales centros urbanos de la región para proletarizarse o mendingar. Por otro lado, si estudiamos el siguiente cuadro de los pueblos "chorotegas del centro" nos daremos cuenta que según APRODIN la población estimada de chorotegas es de 37,500 habitantes, entre los pueblos de Sébaco, Muy muy, Jinotega y Pantasma. Asimismo, el estudio afirma que aproximadamente hay 98,000 habitantes Matagalpa entre gran parte del departamento homónimo, sin embargo, el estudio omite elementos identitario común entre la comunidad de Jinotega, Pantasma Sébaco y Matagalpa, en relación con el mito de la mujer serpiente, la lengua popoluca, los topónimos, la materialidad cultural, la estructura de varas de poder como las de Matagalpa (Rizo, 2014).

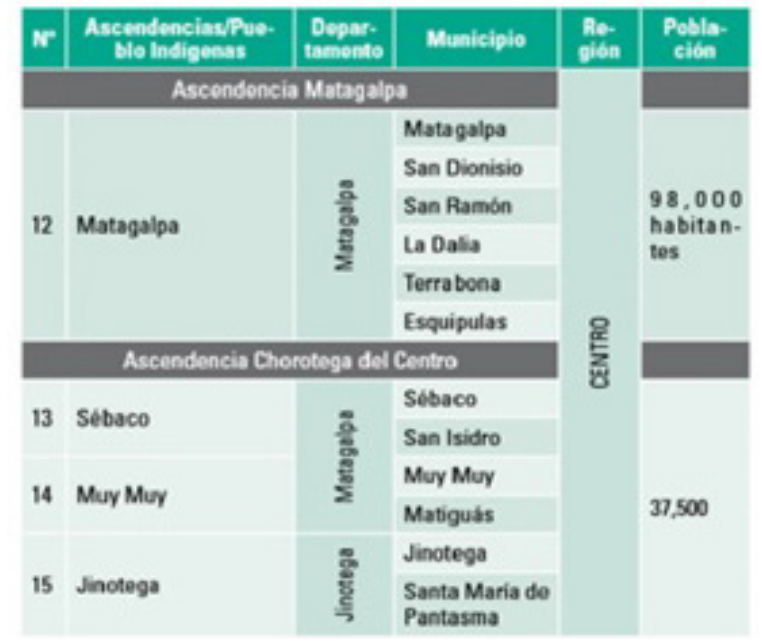

Además, la cultura material es la que se entiende como "el conjunto de valores tangibles que han creado las sociedades en su desarrollo y evolución histórica, entre la cultura material se resaltan; la alimentación, la vivienda, el vestir, el trasporte, instrumentos de trabajo y artísticos, las ocupaciones económicas, la educación, el medio natural". (Guanche, 1983). Sin embargo, como argumenta el historiador Aldo Díaz Lacayo (2007) quien dice: "los pueblos entran a la historia cuando logran superar su prehistoria" de esta manera, podemos decir que, si las comunidades de las Segovia no conocen su origen étnico en común, no podrán trascender a un nivel de consciencia más alto.

Porque el origen se asocia con la auto consciencia étnica y la reflexión del origen hereditario permitiendo exteri- 
orizar el aprendizaje del etnos de cada comunidad y de cada grupo indígena del centro de Nicaragua. No obstante, algunos investigadores y líderes indígenas creen que al denominar que los grupos étnicos de Matagalpa y de Jinotega son Ulúa se altera la construcción del discurso hegemónico de la chorotegización. Sin embargo, como dijo Jesús Guaches (1983) que "la condición de la existencia histórica de la comunidad, nos permite detectar las formas primarias del etnos u ontogénesis".

Siendo la auto consciencia étnica la que responde a un proceso histórico de evolución social, es decir los etnos más antiguos son las tribus, que se caracterizan desde el punto vista general como un todo, además, el estudio de la comunidad primitiva será donde encontramos los orígenes en común del grupo étnico y de su historia. Asimismo, la cultura de los pueblos de las Segovia y su historia es completamente diferente a la cultura tradición Mangue (Chorotega), este hecho se vuelve como la piedra angular de los pueblos indígenas del centro y norte de Nicaragua.

Lo anterior se conecta directamente con las realidades de cada uno de los pueblos de las Segovia, la misma que debe de ser presidida en la consciencia bajo la influencia de la comunidad misma, bajo el lenguaje, el territorio, los hábitos y costumbres comunes, tradiciones culturales y la noción de un origen en común. Por ejemplo, no se le puede pedir a un joven de las Segovia bailar el Güengüense por auto identificarse como chorotega, sin embargo, se le puede preguntar porque se auto identifica con este grupo cultural del pacifico.

Los pueblos indígenas de las Segovia representan un etnos con una conexión cultural individual y colectiva, de origen milenario, al mismo tiempo, el espíritu de resistencia, que contiene una herencia ancestral, que se organiza en todas las comunidades de las Segovia y supera los procesos de etnocidio y trabajo forzado del colonialismo y la colonialidad. (Cruz, 2017). Sus tradiciones se expresan en su cultura espiritual a través de la música, bailes y mitos, que superan la modernidad por la conexión con sus raíces ancestrales, fusionando el espiritualismo y la cultura material, que trasciende lo cotidiano.

Asimismo, las comunidades conservan los lazos psíquicos con los mitos precolombinos, ese "sujeto colectivo" del cual dicen ser descendientes los miembros de cada grupo étnico, aun sabiendo que no son capaces de ras- trear los lazos empíricos de filiación que les une con el otro. Pero si son capaces de retrasar los eslabones genealógicos que les une con sus ancestros, identificando a parientes generacionales léganos y cercanos, que les une a ellos. Es por ello, la responsabilidad de reivindicar al etno histórico de los pueblos indígenas de las Segovia, porque es un compromiso social de cada investigador, donde la base principal es el reconocimiento de la familia, también, a través de los ancestros se auto reconocen y producen los saberes trasmitidos por medio de las relaciones directas entre los parientes generaciones. De esta manera, es que la construcción del discurso de los grupos "chorotegas del centro y norte" es un falso positivo diseñado desde los centros de poder del Pacifico para las Segovia. (Cruz, 2017)

También, la antropología nicaragüense tiene la responsabilidad de abrir las puertas y ventanas al debate público constante sobre la identidad cultural de los pueblos originarios del centro y norte del país, para reconstruir el discurso desde los orígenes históricos, las manifestaciones actuales y las identidades étnicas distorsionadas por las corrientes pacifico céntricas. Para tratar de reivindicar la verdadera identidad cultural de estos pueblos resistentes a la conquista española, a la modernidad y la globalización.

\section{Reflexiones Conclusivas}

Considerando que es importante mencionar que la antropología nicaragüense tiene el adeudo de trabajar por la construcción de la prehistoria e historia de los pueblos étnicos de las Segovia, además, de caracterizar las manifestaciones actuales y saberes de cada región cultural del país, para continuar con las lecturas interpretativas del etnos de cada pueblo del país.

Los componentes culturales de la identidad étnica de los pueblos del centro y norte de Nicaragua, no es chorotega y nunca lo fue, este falso positivo sigue siendo una de las piedras angulares en la ciencia antropológica nacional. Porque la construcción de la auto identidad étnica llamada chorotega del centro y norte no es más que una aseveración sin fundamentos científicos y culturales.

Asimismo, la auto identificación con un pueblo originario es un derecho de cada indígena de las Segovia, sin embargo, dicha aceptación tiene que ser construida por la antropología sociocultural y no por ONG's que 
promueven sus propias agendas ejecutivas. Por otro lado, las prácticas cotidianas que se identifican a través de los elementos ancestrales, articulan el sentido de la pertenencia a los grupos montañeses que fueron un obstáculo en los primeros cincuenta años de conquista.

También, las tradiciones de cada pueblo, las costumbres, las formas de organización social, la vida comunitaria, la trasmisión de generación en generación de los principios, valores, espiritualidad y la dinámica cultural, conservada en las prácticas tradicionales de las poblaciones étnicas del centro y norte donde la cultura material y espiritual continúan presentes, en las formas artísticas y musicales, pero sobretodo en sus sitios arqueológicos que preservan su identidad Chontal, o Ulúa Matagalpa. Además, sólo a través de la reflexión crítica podremos buscar los laberintos de la auto identificación étnica de los grupos de las Segovia, estos elementos tienen que tomar en cuenta las manifestaciones de cada una de las familias étnicas que todavía conservan sus antiguas prácticas en la región centro norte.

\section{Uwe Paul Cruz Olivas}

Licenciado en Historia con mención en arqueología. Máster en Antropología y Liderazgo Social. Presidente de la Fundación Científica Cultural Ulúa Matagalpa y Asesor cultural del Pueblo Indígena Matagalpa. Se ha desempeñado como investigador de la Fundación Ulúa Matagalpa, además de fungir como asesor cultural del Pueblo Indígena Matagalpa. Docente Horario de la UNAN FAREN Matagalpa. 


\section{Referencias}

Andino, E. M. (2016). Identidad estratégica para el desarrollo comunitario en las poblaciones rurales trasfronteriza, Tesis Doctorado. Managua: Unan-Managua.

Andino, E. M. (2017). Más allá de los étnico: procesos identitarios entre reivindicación y prácticas tradicionales, revista raíces $\mathrm{N}^{\circ} 2$.

APRODIN (2012). iNosotros si existimos! La lucha de los pueblos indígenas del Pacifico Centro y Norte Nicaragua por su autodeterminación. Managua: Cooperación austriaca para el desarrollo (ADA).

Batalla, G. B. (1990). México Profundo: una civilización negada. México, Grijalbo.

Cruz, U. P. (2016). Patrón cultural de las comunidades originarias de Siare, Sulingalpa y Fuente Pura, Matagalpa.

Cruz, U. P. (2017). Liderazgo e identidad étnica en las comunidades originarias Apante Grande y Siare, Matagalpa. Tesis de Maestría. Managua: Unan-Managua.

Cruz Paul (2014): "Orígenes del Pueblo Indígena Matagalpa". En Temas Nicaragüense, Managua, Nicaragua.

Constenla Umaña, Adolfo (1991). Las lenguas del Área intermedia, introducido a su estudio, San José, Costa Rica.

Flecher, Larain A. y Ronaldo Salgado Galeano (1990). Informe prospección preliminar de la región I, zona Pueblo Nuevo, municipio de Estelí.

Fletcher, L. A., E. Espinoza Pérez y R. Salgado Galeano (1994). La cerámica de Las Segovia: una visión cronológica inicial. Manuscrito, Departamento de Investigaciones Arqueológicas, Museo Nacional de Nicaragua. Managua.

Grimson, A. (2011). Los límites de la cultura. Critica de las teorías de la identidad. Buenos Aires: Siglo XXI.
Gauche, J. (1993). Procesos etnoculturales de Cuba. La Habana: Editorial Letras Cubanas.

Hooper, John W. (1992). Early Formative Cultures end the Intermediate Area: A background to the Emergence of Social Complexity.

Ibarra Rojas Eugenio, Salgado González Silvia (2010). Áreas Culturales o Regiones históricas en la Explicación de Relaciones sociales de Pueblos Indígenas de Nicaragua y Costa Rica del S XV y XVI.

Incer Barquero, Jaime (2002). Geografía de Dinámica de Nicaragua; 2da edición Híspame Nicaragua.

Kühl Eddy (2010). Raíces del Centro Norte de Nicaragua. Managua, Matagalpa.

Newson, L. A (1987). Indian Survival in colonial Nicaragua. University of Oklahoma Press, Norman.

Lehman, Walter. (1910) Ergebnisse einer Forschungreisse in Mittelamerika und Mexico.

Lacayo, A. D. (2007) Nicaragua una reintrepresación. El inconsciente colectivo. Managua: Aldila.

Salgado González, S. y L. A. Fletcher (1994). Macro regional Relationships between Nicaragua and the Southern Periphery of Mesoamerica, A.D. 300-800.

Salgado González, S. y J. Zambrana Hernández (1994). «El Sector norte de Gran: nuevos datos en la provincia de Granada, Pacífico de Nicaragua». Vínculos 18-19: 121-137.

Rizo Z. Mario (2017): "Aproximación al área cultural Gran Ulúa Matagalpa”. En Fundación Ulúa Matagalpa, Memoria del 1primer congreso. Matagalpa, Nicaragua.

Werner P. (1996) Las Reales de Minas y la Ciudad Perdida de Nueva Segovia, ITSA, Managua. 